\title{
Francine Costet-Tardieu, Les minorités chrétiennes dans la construction de l'Égypte moderne,
} 1922-1952

Paris, Éditions Karthala, coll. « Histoire des mondes chrétiens », 2016, $184 \mathrm{p}$.

\section{Bernard Heyberger}

\section{OpenEdition}

\section{Journals}

Édition électronique

URL : http://journals.openedition.org/assr/28218

DOI : $10.4000 /$ assr.28218

ISSN : $1777-5825$

Éditeur

Éditions de l'EHESS

Édition imprimée

Date de publication : 31 décembre 2016

Pagination : 295

ISSN : 0335-5985

Référence électronique

Bernard Heyberger, «Francine Costet-Tardieu, Les minorités chrétiennes dans la construction de l'Égypte moderne, 1922-1952 », Archives de sciences sociales des religions [En ligne], 176 | octobredécembre 2016, mis en ligne le 17 juillet 2017, consulté le 23 septembre 2020. URL : http:// journals.openedition.org/assr/28218; DOI : https://doi.org/10.4000/assr.28218

Ce document a été généré automatiquement le 23 septembre 2020.

(c) Archives de sciences sociales des religions 


\section{Francine Costet-Tardieu, Les minorités chrétiennes dans la construction de l'Égypte moderne, 1922-1952}

Paris, Éditions Karthala, coll. « Histoire des mondes chrétiens », 2016, $184 \mathrm{p}$.

\section{Bernard Heyberger}

\section{RÉFÉRENCE}

Francine Costet-Tardieu, Les minorités chrétiennes dans la construction de l'Égypte moderne, 1922-1952, Paris, Éditions Karthala, coll. « Histoire des mondes chrétiens », 2016, $184 \mathrm{p}$.

1 Cet ouvrage rédigé dans un style précis et limpide, fondé sur une documentation de première main en arabe, anglais et français, consacré à la première période de l'indépendance égyptienne entre la fin du protectorat britannique (1922) et le renversement de la monarchie (1952), dépasse en fait par les thèmes traités les limites empiriques du sujet. Car à travers cinq chapitres, il aborde des questions qui font encore discussion aujourd'hui, et ne concernent pas que l'Égypte: 1 . Les chrétiens autochtones (coptes) et la nation; 2. Les établissements chrétiens étrangers et les conflits qu'ils suscitent; 3 . La liberté religieuse et les conversions; 4. Les enjeux de l'éducation ; 5. La question du droit personnel et des juridictions communautaires.

2 L'ouvrage montre comment la question des minorités est depuis le $\mathrm{XIX}^{\mathrm{e}}$ siècle intrinsèquement liée aux exemptions de la loi commune accordées aux étrangers (notamment aux missionnaires chrétiens) et à l'ingérence des puissances "protectrices» de ces minorités, dans une période où l'indépendance complète de l'Egypte reste encore à conquérir. Il s'agit en particulier d'obtenir l'abolition des 
Capitulations, héritées de l'empire ottoman, et qui mettent les étrangers dans une situation d'extraterritorialité portant atteinte à la souveraineté égyptienne. Les chrétiens autochtones, notamment les coptes, ont souvent fait les frais d'une confusion dans l'opinion publique entre eux et les étrangers.

3 La place de l'islam dans la définition de la nation égyptienne suscite de très vifs débats, dans une période qui voit émerger une prise de conscience islamique, favorisée par des organisations militantes comme la confrérie des Frères musulmans (fondée en 1928) et enflammée par des campagnes de presse outrées. Il ne s'agit pas d'un problème purement théorique, mais comme le montre l'auteur, d'un sujet aux implications très concrètes, encore débattues de nos jours, comme celui de la construction des églises, de l'enseignement religieux dans les écoles d'État, de la neutralité religieuse des tribunaux et de l'administration. L'exigence d'unité et d'uniformité de la nation entre en contradiction avec la nécessaire référence à la loi islamique, qui introduit de la discrimination à l'égard des non-musulmans. Ainsi, la constitution de 1923 affirme l'égalité devant la loi, proclame que "la liberté de conscience est absolue», mais précise aussi que "l'islam est la religion de l'État». Ce principe resté inscrit dans les constitutions ultérieures, a d'ailleurs été précisé par la constitution de 1971 affirmant que la charia était une source du droit, avant qu'un amendement de 1980 n'en fît la source principale de la législation. Cet énoncé est resté inchangé après la révolution de 2011, dans les textes de 2012 et de 2014.

4 À la liberté de culte, facilement admise (dans certaines limites) par la tradition islamique en faveur des chrétiens et des juifs, s'oppose la liberté de conscience, défendue notamment par les missionnaires et les instances internationales. Cette dernière, qui ouvre la voie à l'individualisme religieux et à la sécularisation, et qui permettrait en particulier à des musulmans de changer de religion, se heurte au tabou irrévocable de la condamnation de l'apostasie par la pensée islamique. De nos jours, les États se référant à l'islam opposent à la notion de "liberté de conscience» de la déclaration universelle des droits de l'homme de 1948 celle de "liberté de religion » ou de «liberté de croyance». Tout changement de religion est interprété comme nonsincère, suscité de l'extérieur par la ruse ou la corruption en vue de diviser la nation.

5 En Égypte comme dans les autres pays se définissant comme musulmans, un droit civil universel et neutre du point de vue confessionnel n'a pas réussi à s'imposer, malgré des tentatives des puissances coloniales pour l'introduire (la Grande-Bretagne en Égypte, en Palestine et en Irak ; la France au Liban et en Syrie). En effet, en matière de mariage, de divorce, de garde d'enfants, et de succession, les représentants des musulmans ne sont pas prêts à se soumettre à un droit qui ne suivrait pas les préceptes de la charia. De ce fait, les non-musulmans conservent également leur propre droit personnel. En Égypte, les juridictions ont été unifiées : les tribunaux confessionnels ont été abolis, leurs compétences transférées aux tribunaux civils. Mais la législation elle-même n'a pas été unifiée, ce qui crée des inimaginables situations d'imbroglio.

6 L'exposé des faits dans l'ouvrage révèle à quel point les positions des différents acteurs se déterminent dans l'interaction et le mimétisme des uns par rapport aux autres. L'identité égyptienne construite contre l'occupant britannique et occidental trouve naturellement sa source dans l'islam et l'antioccidentalisme. En réaction, les coptes se replient toujours davantage sur leurs institutions communautaires et sur une culture spécifiquement égyptienne et chrétienne. Les gouvernements égyptiens successifs, coincés entre la nécessité de passer des compromis avec les Britanniques et de gagner 
de la légitimité aux yeux des Égyptiens, sont souvent amenés à faire des concessions aux militants islamistes. L'occupant britannique pour sa part, cherchant à se désengager en protégeant ses intérêts, s'appuie sur la Société des Nations et sur le droit international pour tenter de préserver l'avenir des établissements chrétiens étrangers dans le pays. Les coptes doivent se démarquer des occupants et des missionnaires en s'affirmant Égyptiens avant tout, mais en tentant de ne pas se voir entièrement soumis à un système politique fondé sur l'islam.

7 Chaque camp, enfin, est traversé par ses propres contradictions et par ses propres compétitions. Ainsi, Al-Azhar doit faire face aux Frères musulmans et à un Comité pour la défense de l'islam qui lui contestent son autorité. La communauté copte est traversée par un conflit sans fin pour le leadership entre les notables laïcs et le clergé. Et on ne peut réduire les missionnaires à de simples agents de l'impérialisme britannique, sachant que le gouvernement anglais ne soutient pas systématiquement les revendications des missionnaires, et que ces derniers n'ont d'ailleurs pas une vision uniforme de leur avenir et de l'attitude à adopter face aux musulmans. 